\title{
ORBITAL FLOOR RECONSTRUCTION WITH TRANS-ANTRAL APPROACH USING ENDOSCOPE ACASE REPORT
}

\section{Case \\ Report}

\author{
${ }^{1}$ Rishabh Giri, ${ }^{2}$ Vikas Kunwar Singh, ${ }^{3}$ Ruchika Tiwari, ${ }^{4}$ Gaurang Thanvi \\ ${ }^{1-4}$ Department of Oral and Maxillofacial Surgery, \\ Mahatma Gandhi Dental College \& Hospital, Jaipur
}

\begin{abstract}
:
Background and objective: Orbital floor fractures are very common in current day to day scenario. Till date different treatment modalities have been tried to reconstruct the orbital fractures. Conventionally various transorbital approaches have been used. But in cases where there is involvement of posterior part of orbit there is drawback of incomplete accessibility. To overcome this endoscopic assistance tends to get mandatory through trans-antral approach for better visualization, providing a good alternative to conventional approach.

Case Report: A 55-year-old male patient with pure blowout fracture along with persistent diplopia and enophthalmos was operated with sub tarsal approach along with trans antral approach using endoscope.

Result: The post-surgical results were satisfactory in respect to correction of diplopia and enophthalmos.

Conclusion: Conventional approach assisted with endoscope provides a new method of managing Orbital floor fractures improving treatment outcomes.
\end{abstract}

\author{
Key words: \\ Orbital fractures, \\ Trans antral, Endoscope, \\ Diplopia, Enophthalmos \\ Source of support : Nil \\ Conflict of interest: None
}

INTRODUCTION : Orbital floor fractures are very common in current day to day scenario. Orbital floor fractures were first described by Mckenzie in 1844.[1] Later Smith and Regan gave the term orbital blow out fractures, describes a traumatic deformity due to impact of blunt object larger than the orbital aperture mostly involving orbital floor and medial wall of orbit.[2] The theories suggested for this are Hydraulic theory which is related to increased intra orbital pressure. Buckling theory which suggests transmission of pressure posteriorly to orbital rim leading to buckling of orbital floor.[3] Orbital blowout fractures comprised of pure not involving of orbital rim and impure involving of orbital rim. Different aetiologies for orbital fractures are sports injury, road traffic accidents, fall from height, interpersonal violence and industrial accidents. Clinical features for orbital fractures include periocular oedema, subconjunctival haemorrhage, diplopia, subcutaneous emphysema in acute phase.[4]
Diplopia may present due to entrapment of inferior oblique muscle[5], fat or orbital tissue. Enophthalmos is a common presenting symptom in patients who sustained orbital blow out fracture. The main aim in treating orbital fracture is to reduce the prolapsed orbital tissue and reconstruct the floor for management of diplopia and enophthalmos.

Endoscopic approach is a minimally invasive approach along with better accessibility apart from conventional transorbital approach alone which has its own drawbacks. This article suggests sub tarsal along with trans antral approach assisted with endoscope which provides a better outcome in cases of orbital floor fractures.

CASE REPORT : A 55-year-old male patient came in the casualty of Mahatma Gandhi hospital, Jaipur on 9/10/19 with chief complaint of pain and double vision in the left eye after trauma. Patient had history of injury to his left side of face due to fall from bike 1 weeks before with presence of persistent 
diplopia since the time of injury. On examination, subconjunctival haemorrhage was noted in the left eye. Mild tenderness was noted in left infraorbital rim without any step deformity. Eye movements were normal in all the gazes except in upper gaze. Clinical evaluation revealed evidence of orbital dystopia with enophthalmos.

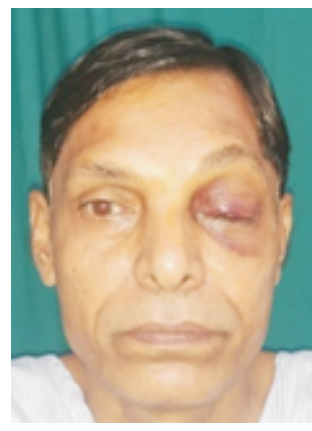

A)Frontal profile Figure 1. Pre- Operative Pictures

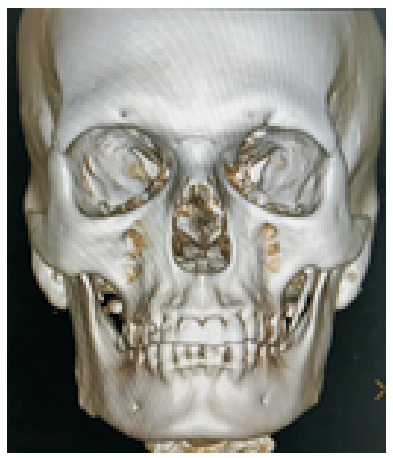

A) 3D CTFace

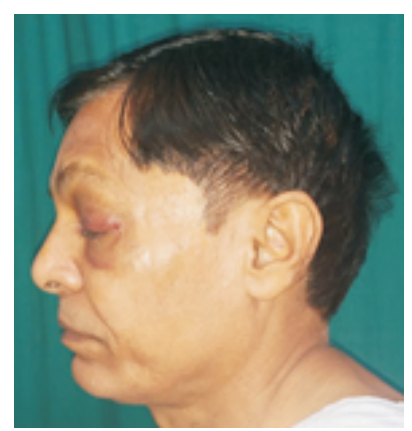

B)Lateral profile

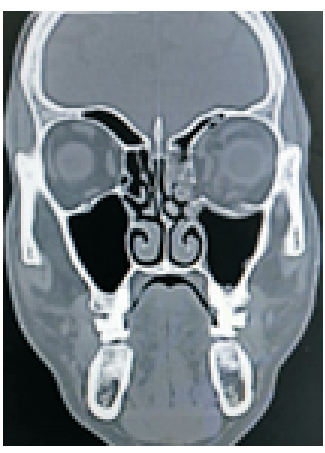

B) Coronal section
Figure 2. CT Scan Showing pure blowout fracture

A CT scan of the orbit with $0.625 \mathrm{~mm}$ slices revealed the fracture of left orbital floor with herniation of orbital contents into the maxillary antrum along with entrapment of inferior rectus muscle and diagnosed as "pure blowout fracture of left orbital floor".

All the details of the surgery were explained to the patient \& consent was obtained. The surgery for orbital defect repair was planned under general anaesthesia with oral intubation along with sub tarsal and trans antral approach. Sub tarsal approach was given to expose the orbital floor defect transcutaneous. A buccal vestibular incision was given to intraorally to expose the anterior sinus wall. Bony window of $1 \times 2 \mathrm{~cm}$ was created on the sinus wall for accessibility to entrapped orbital fat. 30-degree endoscope being used for visualization. The entrapped fat was released with the freer. Forced duction test was performed for any entrapment and there was no restriction to eye movement assessed.

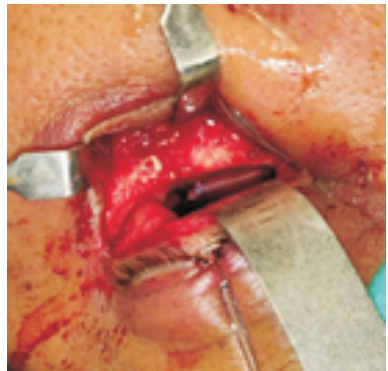

A) Exposure of orbital Floor through

Sub-tarsal incision

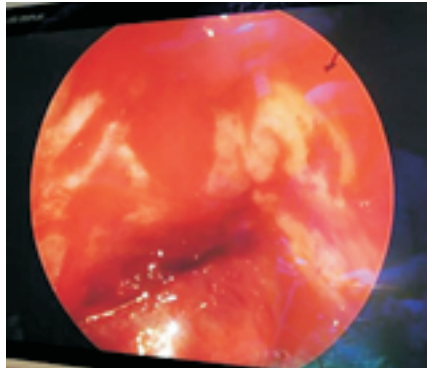

B) Endoscopic

Trans- Antral view showing herniation of Orbital Fat

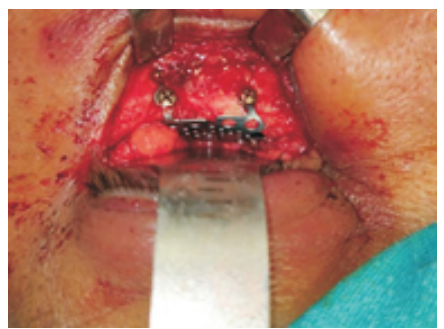

C) Orbital Floor Titanium Mesh

Figure 3. Intra operative Pictures

The titanium orbital mesh was placed through sub tarsal approach. The proper placement of mesh was assessed with endoscope over orbital defect. Closure was done in layers periosteum, muscle and skin with prolene suture. The intra oral trans antral window was closed by placing bone back to the its previous position. Closure was done with 3-0 vicryl. Regular prophylactic antibiotics along with nasal decongestants were prescribed. The patient was asked not to blow his nose along with soft and liquid diet. The results were satisfactory with correction of enopthalmous and diplopia.
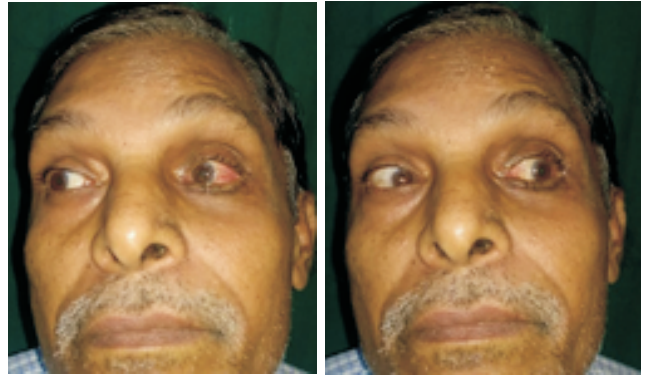

A) Side to side eye movements

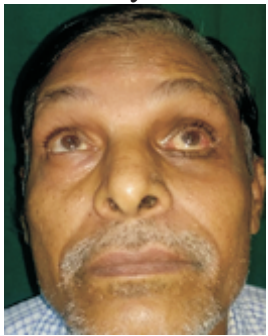

B) upward gaze showing no restriction in left eye movement 


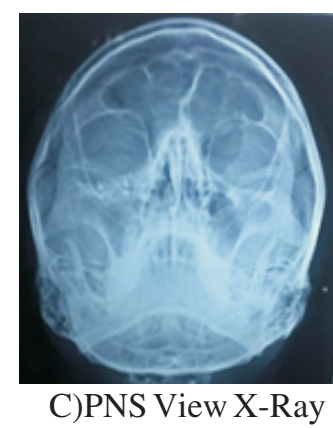

Figure 4. Post Op Pictures

DISCUSSION: Conventionally transorbital approach was being used for orbital floor reconstruction but because of its limitation such as lack of proper visualization in cases of posterior tissue entrapment the need for endoscope came into existence along with trans antral and transcutaneous approach. Endoscope assisted trans antral approach has its advantage over conventional approach such as precise identification of entrapment of orbital fat in posterior region along with assessment of correct placement of implant. Burnstine6 gave the concept of orbital exploration for the first time. Various studies show the benefit of trans antral and transcutaneous approach assisted with endoscope. The trans antral approach was first described by Walter.[7] This combined approach is well applicable in cases of orbital floor fractures with findings of diplopia due to muscle entrapment and in enophthalmos.

Our case was done with sub tarsal approach to expose the orbital defect followed by trans antral approach assisted with 30 -degree endoscope intra orally.[8,9,10] The herniated orbital fat tissue entrapment was released with freer with placement of titanium orbital mesh. Confirmation of the release of the fat tissue was done with forced duction test. Satisfactory results were obtained with correction of diplopia and enophthalmos.

CONCLUSION : In cases where need of better visualization, conventional approach along with Trans- Antral endoscopic approach provides a new method of managing Orbital floor fractures hence improving treatment outcomes.

\section{REFERENCES:}

1. Ng P, Chu C, Young N, Soo M (1996) Imaging of orbital floor fractures. Australas Radiol 40: 264-268.

2. Smith B, Regan WfJr (1957) Blow-out fracture of the orbit; mechanism and correction of internal orbital fracture. Am J Ophthalmol 44: 733-739.

3. Fujino T (1974) Experimental "blowout" fracture of the orbit. PlastReconstrSurg 54: 81-82.
4. Burnstine MA (2002) Clinical recommendations for repair of isolated orbital floor fractures: an evidencebased analysis. Ophthalmology 109: 1207-1210.

5. Lyon DB, Newman SA (1989) Evidence of direct damage to extraocular muscles as a cause of diplopia following orbital trauma. Ophthal Plast Reconstr Surg 5: 81-91.

6. Burnsine MA. Clinical recommendations for repair of isolated orbital floor fractures: an evidence-based analysis. Ophthalmology. 2002;109:1207-1213. doi: 10.1016/S0161-6420(02)01057-6.

7. Walter WL. Early surgical repair of blowout fracture of the orbital floor by using the transantral approach. South Med J. 1972;65:1229-1243. doi: 10.1097/00007611197210000-00014.

8. Saunders CJ, Whetzel TP, Stokes RB, Wong GB, Stevenson TR. Transantral endoscopic orbital floor exploration: a cadaver and clinical study. Plast Reconstr Surg. 1997;100:575-581. doi: 10.1097/00006534199709000-00003.

9. Fernandes R, Fattahi T, Steinberg B, et al. Endoscopic repair of isolated orbital floor fracture with implant placement. J Oral Maxillofac Surg. 2007;65:1449-1453. doi: 10.1016/j.joms.2006.10.080.

10. Carton A, Hislop S. Orbital floor injury with extraocular muscle entrapment following functional endoscopic sinus surgery. Br J Oral Maxillofac Surg. 2000;38:82-83. doi: 10.1054/bjom.2000.0401.

\section{CORRESPONDING AUTHOR:}

\section{Dr. Rishabh Giri}

Department of Oral and Maxillofacial surgery, Mahatma Gandhi Dental College and Hospital, Jaipur, Rajasthan.

Email: giririshabh@gmail.com 